Original article

\title{
The effects of tempe extract on the oxidative stress marker and lung pathology in tuberculosis Wistar rat
}

\author{
Lusiani Tjandra, Budhi Setiawan, Kartika Ishartadiati, Sri Lestari Utami, Jimmy Hadi Widjaja \\ Wijaya Kusuma University, Surabaya, East Java, Indonesia
}

Received 10 December 2020, Revised 7 June 2021, Accepted 27 October 2021

(C) 2020, Russian Open Medical Journal

Abstract: Background and Objective - Tempe (fermented soybean) has the potential as an affordable nutritional support alternative during tuberculosis (TB) infection. The purpose of the study was to assess the efficacy of supplementation with the ethanolic extract of Tempe on the oxidative stress markers alleviation and histological changes in male Wistar rats infected with Mycobacterium tuberculosis. Material and Methods - Thirty-five male Wistar rats were divided randomly into five groups and infected by Mycobacterium tuberculosis strain H37RV intratracheally. Total antioxidant capacity (TAC) and Thiobarbituric Acid Reaction (TBARS) levels were assessed using a colorimetric method while C-reactive protein (CRP) was measured by Elisa method. The lung damage was scored using histopathological parameters.

Results - There were no significant differences in the TBARS levels and CRP concentrations compared to control. Tempe extract increased the TAC level at $200(p=0.011), 400(p=0.027)$, and $800(p=0.029) \mathrm{kg} /$ body weight concentrations compared to control. Perivasculitis and alveolitis mean scores were lower $(p<0.05)$ than control in all supplement groups. Additionally, the mean scores of peribronchiolitis among supplementation groups were decreased $(p<0.05)$ in the 200 and $800 \mathrm{mg} / \mathrm{kg}$ body weight, while the granuloma mean score was lower in the $800 \mathrm{mg} / \mathrm{kg}$ body weight compared to control.

Conclusions - Tempe extract may have a weak efficacy in improving the antioxidant capacity and lung histological condition in TB rat models.

Keywords: antioxidant, fermented soybean, oxidative stress, soy isoflavones, tempe, tuberculosis.

Cite as Tjandra L, Setiawan B, Ishartadiati K, Utami SL, Widjaja JH. The effects of tempe extract on the oxidative stress marker and lung pathology in tuberculosis Wistar rat. Russian Open Medical Journal 2021; 10: e0412.

Correspondence to Budhi Setiawan. Address: Department of Pharmacology, Faculty of Medicine, Wijaya Kusuma University, Jalan Dukuh Kupang XXV/54, Surabaya, East Java, Indonesia. Phone: (+62-31) 5686531. E-mail: budhisetiawan@uwks.ac.id.

\section{Introduction}

Tempe is a fermented soybean with high nutritional and economic value originating from Indonesia. Soybean contains soy isoflavone that has antioxidant (AO) activity and it might have a beneficial effect on oxidative stress [1]. Antioxidant activity of soy isoflavone may have a protective effect on acute lung tissue injury due to oxidative stress. It has been shown that soy isoflavone exerts a beneficial effect on lung tissue after radiation [2]. Solidstate fermentation (SSF) using Rhizopus spp. was used to enhance the isoflavone aglycones, as well as the total phenolic and antioxidant activity [3]. The fermentation process may cause an increased positive effect on human health because of the higher bioavailability of aglycone isoflavones from soybeans and it is faster to be absorbed as well [4].

Tuberculosis (TB) is the leading cause of global deaths from infectious disease and still a major concern in public health [5]. According to the WHO global tuberculosis report, there were approximately 10 million TB cases in 2018. Moreover, the estimation of death caused by TB was 1.2 million among Human Immunodeficiency Virus (HIV) negative people and an additional 251,000 patients with HIV in the same year [6]. Loss of body weight, wasting, and malaise are the common symptoms of TB infection. Studies have shown that nutritional support during TB can accelerate weight gain and lead to muscle strength improvement [7].

Inflammation plays an important role in the host's defensive mechanism against infection, including tuberculosis. C-reactive protein (CRP) is an acute phase of inflammation and an unspecified marker of inflammation that commonly measured in active tuberculosis patients since its level increases during infections. This marker increases in active TB and does not depend on the severity and the location of the infection [8] so it can be used for TB prognosis. This test also reflects the course of the disease and the efficacy of the drugs used to combat TB infection [9].

Moreover, malondialdehyde (MDA) measurements are used to monitor lipid peroxidation in biological samples. Lipid peroxidation is the result of tissue damage caused by free radicals and subsequently creates various pathological conditions. Serum MDA concentrations reflect the levels of oxidative stress and often increased in TB infections [10]. The level of MDA in the serum can be assessed using thiobarbituric acid reactive substances (TBARS) assays. 
During TB infection, oxidative stress can be prominent and cause the evident histological damage to the lung. Macrophages come in contact with bacteria and generate a large number of reactive oxygen species (ROS). If there is an imbalanced redox mechanism, these ROS can induce lipid peroxidation and eventually result in DNA damage [11]. It has been shown that the pathological response in the lung positively correlates with the TB bacterial load [12].

Previous studies on rats have shown the beneficial effects of soy isoflavones on antioxidant status in several conditions. [13] described that the supplementation of genistein, soy protein isolates from tempe, increase the MDA and TAC, and decrease the CRP in diabetic rats induced by streptozotocin (STZ). Oral administration of soy isoflavones for 21 days to gamma-ray irradiated male Wistar rats had a positive effect on the activity of TAC, MDA, and CRP in the liver and erythrocytes when compared to animals without soy isoflavone administration [14]. Additionally, a high soy isoflavone diet was able to reduce the level of nitric oxide and MDA as well as increase the TAC in ovariectomized rats [15]

There are a few reports about the efficacy of tempe extracts on the tuberculosis infection up to date. The data about the antioxidant effect of soy isoflavone to lung histopathology in the TB animal model is also limited. Considering the potential for the positive influence of soy isoflavones in tempe supplementation, this study aims to analyze whether the supplementation of ethanolic extract of tempe has a positive effect on oxidative stress biomarkers and lung histological condition of male Wistar rats infected by Mycobacterium tuberculosis.

\section{Material and Methods}

\section{Reagents and chemicals}

Soybeans (Glycine max L. Merr var. Grobogan) were obtained from a research institute for various beans and tubers in Malang, East Java, Indonesia. The tempe starter, containing Rhizopus oligosporus and rice flour for the SSF, was purchased from a local market in Surabaya, Indonesia. The brand name of the tempe starter was RaprimaTM and it was produced by Aneka Fermentasi Industri (AFI), Bandung, Indonesia.

\section{Preparation of tempe samples}

The tempe sample was prepared using a method in which the soybeans were boiled twice before fermentation. Concisely, $500 \mathrm{~g}$ of yellow soybeans were boiled in $100 \circ \mathrm{C}$ pre-heated tap water for 30 minutes. After that, the water used for boiling was discarded and the wet method was used to peel the boiled soybeans. Dehulling was performed by hand to rub the hulls from the cotyledons until nearly $90 \%$ of the separated skins were removed from the water. The hulls floating on the top of the water were removed as the water was drained. Then, the soybean seeds were soaked overnight for 12 hours in fresh tap water, with the water level was maintained at $5 \mathrm{~cm}$ over the beans, at room temperature $\left(27-30^{\circ} \mathrm{C}\right)$. The second boiling was carried out in pre-heated fresh tap water at $100^{\circ} \mathrm{C}$ for 30 minutes. After removing the water, the soybeans were spread homogeneously on a flat surface to allow them to cool to room temperature. The cool down step was done 30 minutes before the soybeans were inoculated with the starter. One gram of a commercial tempe starter (RaprimaTM), which contained $R$. oligosporus, was added and stirred gently to inoculate the soybeans uniformly. After 20 minutes of stirring, the inoculated soybeans were then transferred into sealed plastic bags that had been perforated with a toothpick. They were placed in a room at a lukewarm temperature $\left(28 \pm 2^{\circ} \mathrm{C}\right)$ for 48 hours. After the incubation period, the tempe was kept at $-10^{\circ} \mathrm{C}$ until the next preparation.

\section{Uncooked tempe extraction}

Extraction was performed based on the method by $\mathrm{Xu}$ and Chang [16]. Tempe samples were dried at a temperature of 40 $45^{\circ} \mathrm{C}$ for 24 hours. The dried tempe was crushed until it became powder (60 mesh). Tempe powder ( $0.5 \mathrm{~g}$ ) and $70 \%$ ethanol were stirred using a vortex and then stored in a dark room for 24 hours to preserve its light-sensitive bioactive compounds. The filtrate was separated using centrifugation $(3000 \mathrm{rpm})$, then filtered. After the first filtrate was obtained, its residue was added to $5 \mathrm{~mL}$ of $70 \%$ ethanol again, and then the previous process was repeated. The first and the second filtrate were mixed and then evaporated by a rotary evaporator at $60^{\circ} \mathrm{C}$.

\section{Total polyphenol content and total flavonoid analyses}

Total polyphenol content (TPC) was determined using Folin Ciocalteu's method [17]. As much as $0.1 \mathrm{~mL}$ of extract and $0.5 \mathrm{~mL}$ of Folin Ciocalteu's reagent were mixed with pure $\mathrm{H} 2 \mathrm{O}$ (1:1) in a tube, vortexed, and allowed to stand for 8 mins. Then, $4.5 \mathrm{~mL}$ of $2 \%$ sodium carbonate solution was added, vortexed, and incubated in a dark room for 1 hour at room temperature. The absorbance of the resulting blue complex was measured at $770 \mathrm{~nm}$ using a spectrophotometer (Genesys 20, Thermo Fisher scientific spectrophotometer). Methanol was used as the blank and catechin was used as the standard.

About $1 \mathrm{~g}$ of the sample was treated in a $100 \mathrm{~mL}$ round-bottom flask with $1.0 \mathrm{~mL}$ of hexamethylenetetramine $0.5 \%(\mathrm{w} / \mathrm{v}), 20.0 \mathrm{~mL}$ of acetone, and $2.0 \mathrm{~mL}$ of hydrochloric acid. The mixture was refluxed on a water bath for 2 hours and filtered through small cotton wool into a $100 \mathrm{~mL}$ flask. The filter was washed twice with $20.0 \mathrm{~mL}$ of acetone and the washings were refluxed for 10 minutes. When the solutions were cooled down, they were filtered and made up to $100 \mathrm{~mL}$ with acetone. Twenty $\mathrm{mL}$ of this solution was transferred into a separating funnel and extracted with 15.0 $\mathrm{mL}$ of ethyl acetate. The extraction was repeated three times, using $10.0 \mathrm{~mL}$ of ethyl acetate each time, and the combined organic phases were washed twice with $50 \mathrm{~mL}$ of water and made up to $50 \mathrm{~mL}$ with ethyl acetate. A volume of $2.0 \mathrm{~mL}$ of AlCl3 $2 \%$ $(\mathrm{w} / \mathrm{v})$ in ethanol was added to $10.0 \mathrm{~mL}$ of SS and the solution was made up to $25.0 \mathrm{~mL}$ with a methanolic solution of acetic acid $0.5 \%$ (v/v) (Probe Solution, PS). At the same time, $10.0 \mathrm{~mL}$ of SS were made up to $25.0 \mathrm{~mL}$ with methanol/acetic acid solution (Contrast Solution, CS).

\section{DPPH assay}

The antioxidant activity of the tempe ethanol extract was measured with the 2,2-diphenyl-1-picrylhydrazyl (DPPH) method with slight modifications. Briefly, $3.8 \mathrm{~mL}$ of ethanol DPPH solution was freshly prepared and mixed with $0.2 \mathrm{~mL}$ of tempe extract in a test tube. As a blank, $70 \%$ ethanol $(0.2 \mathrm{~mL})$ was used and mixed with $3.8 \mathrm{~mL}$ of ethanol DPPH. The test tube was then incubated in the dark for 30 minutes at room temperature. The final absorbance was then measured by using a spectrophotometer 
(Genesys 20, Thermo Fisher scientific spectrophotometer) at 517 $\mathrm{nm}$ against the blank. The percentage of radicals' inhibition was calculated using the following formula:

\{1- (absorbance of the sample/absorbance of the control)\} (1)

\section{Tempe extracts administration to TB animal model}

Albino male Wistar rats, weighing between $150-200 \mathrm{~g}$, were infected with $50 \mu \mathrm{L}$ of the solution containing $108 / \mathrm{mL}$ of Mycobacterium tuberculosis strain H37RV through the trachea. Mycobacterium tuberculosis bacteria were taken from the stock grown in Lowenstein-Jensen (L) media for 2-3 weeks. Thirty-five rats were infected with Mycobacterium tuberculosis intratracheally and then divided randomly into five groups. Randomization was done using www.randomizer.org to get the random numbers. The extract administration was done orally since this study was designed to find the positive effect of food-based supplementation. Additionally, a previous study has administered per oral by doses ranging from $200 \mathrm{mg} / \mathrm{kg}$ BW to $1000 \mathrm{mg} / \mathrm{kg} \mathrm{BW}$ nutrient-enriched soybean tempe to mice [18]. Therefore, the first, second, and third groups received the tempe ethanol extract via oral gavage with a dose of $200 \mathrm{mg} / \mathrm{kg} \mathrm{BW}, 400 \mathrm{mg} / \mathrm{kg} \mathrm{BW}$, and 800 $\mathrm{mg} / \mathrm{kg} \mathrm{BW}$; the fourth and the fifth groups served as negative controls (CMC-Na), and another group to be sacrificed for infection confirmation under general anesthesia. The supplementation was carried out on the 30th day following the infection and given for 14 days. It is commonly accepted that the TB incubation period is between two to twelve weeks and effective treatment using TB chemotherapy may significantly decrease the infections within two weeks.

At the end of the 6th week, the sample collection was conducted for all the rats as a similar study had described [19]. Rats were anesthetized during the blood and tissue sample collection. An appropriate needle was used to withdraw the blood sample from a ventricle of the heart after a thoracotomy procedure. Then, the lung tissues were taken for further histopathological analyses.

\section{Lung tissue pathology analysis}

The lung tissue damage was assessed based on the Dorman score and conducted by a professional pathologist. The histopathological parameters of peribronchiolitis, perivasculitis, alveolitis, and granuloma formation were each semi-quantitatively scored as absent, minimal, slight, moderate, marked, or strong; noted as $0,1,2,3,4$, and 5 , respectively. In this scoring system, the frequency and the severity of the lesions were also incorporated. Granuloma formation was scored by estimating the occupied area of the lung section. For each point, the lungs of seven rats were examined, and the mean score of each of the four histological parameters was calculated. The mean scores of the four parameters mentioned above were added to evaluate the strength of the total pathological response. Thus, the maximum score was 20 [12].

\section{Oxidative stress biomarker analyses}

Membrane lipid peroxidation was estimated by the end-point generation of Thiobarbituric acid reactive substances (TBARS) using the Quantichrome TM TBARS Assay Kit (DTBA-100). These substances are mainly malondialdehydes (MDAs) that are formed during the decomposition of lipid peroxidation products. The assay is based on the reaction of TBARS with thiobarbituric acid (TBA) to develop a pink-colored product. The color intensity at $535 \mathrm{~nm}$ is directly proportional to the concentration of TBARS in the sample [20].

Rat serum samples were assayed for TAC using the commercially available Total Antioxidant Status (TAS) kit (Quantichrome TM Antioxidant Assay Kit (DTAC-100)). The assay measures the total antioxidant capacity, in which $\mathrm{Cu} 2+$ is reduced by an antioxidant to $\mathrm{Cu}+$. The resulting $\mathrm{Cu}+$ forms a specially colored complex with a dye reagent. The color intensity at $570 \mathrm{~nm}$ is proportional to TAC in the sample [21].

Serum CRP concentrations were determined in duplicate with the commercially available enzyme-linked immunosorbent assay (ELISA) kit (Bioassay Technology Laboratory). CRP was added to the wells that were pre-coated with CRP monoclonal antibody. After incubation, the unbound biotin-conjugated anti-mouse CRP antibody was added as well to bound the mouse CRP. After incubation, the unbound biotin-conjugated anti-mouse CRP antibody was washed away during the washing step. Streptavidin HRP was added and bound to the biotin-conjugated anti-mouse CRP antibody. After incubation, the unbound Streptavidin HRP has washed away during the washing step. The substrate solution was then added and the developed color was in proportion to the amount of mouse CRP. The reaction was terminated by the addition of an acidic stop solution and the absorbance was measured at $450 \mathrm{~nm}$ [22].

\section{Statistical analysis}

The results were expressed as means and standard deviations. Each sample, soybean, tempe, and their ethanol extract, was measured twice. The Kolmogorov-Smirnov test was used to test whether samples come from a normal distribution or not. The means comparison of more than two groups were analyzed by the univariate analysis of variance (UNIANOVA), followed by the Least Significant Differences (LSD) post hoc test if the samples were normally distributed. Kruskal-Wallis $\mathrm{H}$ test (nonparametric test) was applied for the alternative of UNIANOVA if the distribution of the samples was not normal and Mann-Whitney $U$ test was applied in post hoc test. The results of total flavonoids, TAC, TBARS and DPPH were analyzed using UNIANOVA and total polyphenols, lung pathology scores and CRP were assessed by Kruskal-Wallis $\mathrm{H}$ test. The cutoff of the statistical significance level was set at $p<0.05$. The statistical analyses were done through the commercially available Statistical Package for Social Sciences software (IBM Corp. Released 2013. IBM SPSS Statistics for Windows (Version 23.0) Armonk, NY: IBM Corp.).

\section{Results}

Total polyphenols and total flavonoid levels in tempe extract were found to be higher compared to those in soybeans and uncooked tempe. Uncooked tempe showed lower total polyphenols and total flavonoids than soybean and tempe extract with $67.92 \mathrm{mg} \mathrm{GAE} / 100 \mathrm{~g}$ sample and $19.01 \mathrm{mg}$ routine equivalent/100 g sample, respectively. On the other hand, tempe extract showed the highest total polyphenols and total flavonoids with $853.00 \mathrm{mg} \mathrm{GAE} / 100 \mathrm{~g}$ samples and $34.36 \mathrm{mg}$ routine equivalent/100 g samples, respectively. The results of the DPPH assay showed soybean (20.01\%) and uncooked tempe $(21.70 \%)$ were relatively comparable. However, Tempe extract $(30.72 \%)$ was higher than both. Hence, the ethanol extract of tempe has the 
highest result in antioxidant activity among other samples, measured by DPPH assay, in this study (Figure 1).

The administration of tempe ethanol extract showed a significant increase in TAC compared to controls. The increase was not dose-dependent because there was no difference in TAC levels between each dose (Table 1). Significant improvement was obtained by the administration of $200 \mathrm{mg} / \mathrm{kg}$ BW $(252.54 \pm 33.80$ $\mu \mathrm{M}$ Trolox Equivalents) compared to the control (197.94 \pm 33.43 $\mu \mathrm{M}$ Trolox Equivalents). While the administration of $400 \mathrm{mg} / \mathrm{kg}$ BW (244.84 $\pm 22.94 \mu \mathrm{M}$ Trolox Equivalents) and $800 \mathrm{mg} / \mathrm{kg}$ BW (244.29 $\pm 52.54 \mu \mathrm{M}$ Trolox Equivalents) did not differ significantly from $200 \mathrm{mg} / \mathrm{kg}$ BW.

Oral administration of tempe extract showed no significant change in serum CRP levels compared to controls. Table 2 showed that compared to CMC-Na $(2.57 \mathrm{mg} / \mathrm{L}), 200 \mathrm{mg} / \mathrm{kg}$ BW dose $(2.74 \mathrm{mg} / \mathrm{L}), 400 \mathrm{mg} / \mathrm{kg}$ BW $(2.90 \mathrm{mg} / \mathrm{L})$, and $800 \mathrm{mg} / \mathrm{kg} \mathrm{BW}$ $(2.65 \mathrm{mg} / \mathrm{L})$ showed the CRP levels that were not significantly different $(p>0.05)$. TBARS levels in TB models did not show a significant decrease after tempe extract administration for 14 days compared to controls. Control CMC-Na (0.90 \pm 0.22 TBARS $\mu M$ MDA equivalents) compared to $200 \mathrm{mg} / \mathrm{kg}$ BW $(1.04 \pm 0.28$ TBARS $\mu \mathrm{M}$ MDA equivalents) dose, $400 \mathrm{mg} / \mathrm{kg}$ BW $(1.16 \pm 0.34 \mu \mathrm{M}$ MDA equivalents), and $800 \mathrm{mg} / \mathrm{kg} \mathrm{BW}(1.09 \pm 0.21 \mu \mathrm{M}$ MDA equivalents) did not show significant differences $(p>0.05)$.

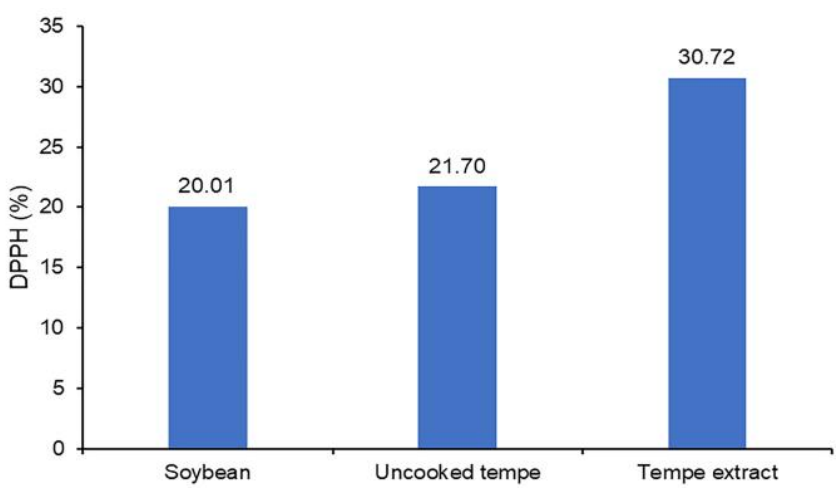

Figure 1. Antioxidant activity assessed using DPPH assay. Values with different superscript letters $(a-c)$ in the figure are significantly different $(p<0.05)$.
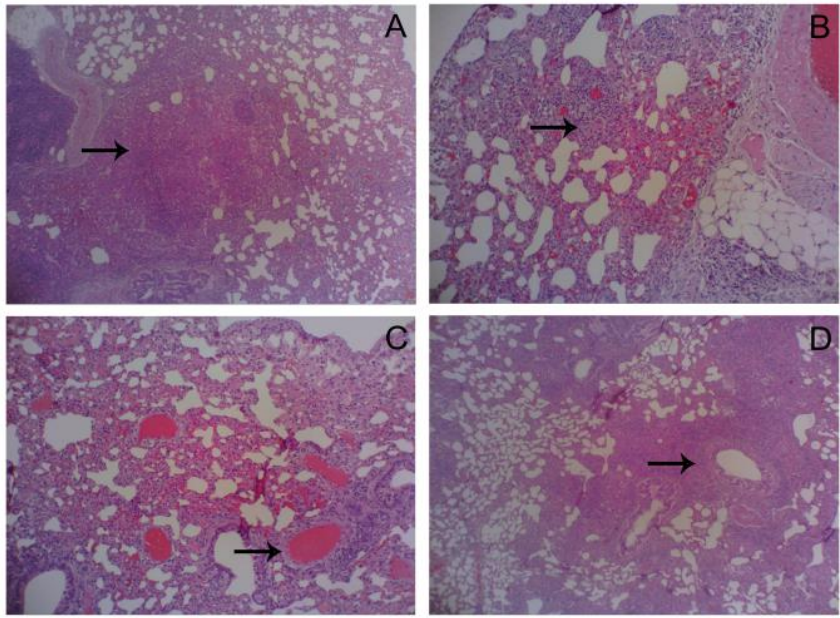

Figure 2. The histological analysis result of the lung tissue: alveolitis (A), granuloma (B), peribronchiolitis (C), and perivasculitis (D).
Table 1. Total polyphenol, total flavonoid, and DPPH assay of soybean, uncooked tempe, and ethanol extract of tempe

\begin{tabular}{lcc}
\hline & Total polyphenol $^{+}$ & Total $_{\text {flavonoid }}{ }^{++}$ \\
\hline Soybean & $146.20^{\mathrm{b}}$ & $22.87^{\mathrm{b}}$ \\
Uncooked tempe & $67.92^{\mathrm{a}}$ & $19.01^{\mathrm{a}}$ \\
Tempe extract & $853.45^{\mathrm{c}}$ & $34.36^{\mathrm{c}}$ \\
\hline Median $(\mathrm{n}=2){ }^{+} \mathrm{mg}$ Gallic Acid Equivalents $(\mathrm{GAE}) / 100 \mathrm{~g}$ sample; ${ }^{++} \mathrm{mg}$
\end{tabular}

Median ( $\mathrm{n}=2) .{ }^{\dagger} \mathrm{mg}$ Gallic Acid Equivalents (GAE)/100 g sample; ${ }^{\text {t† }} \mathrm{mg}$ routine equivalent $/ 100 \mathrm{~g}$ sample. Values with different superscript letters $(a-c)$ in the same row are significantly different $(p<0.05)$ based on the Kruskal-Wallis $\mathrm{H}$ test (nonparametric).

Table 2. Oxidative stress biomarker analysis results

\begin{tabular}{|c|c|c|c|}
\hline & $C R P(\mathrm{mg} / \mathrm{L})^{*}$ & TBARS $(\mu M)^{* * t}$ & $T A C(\mu M)^{* *+t}$ \\
\hline & $57(2.5$ & $0.90 \pm 0.22^{\mathrm{a}}$ & $\pm 33.43^{a}$ \\
\hline & 74 & & \\
\hline & 2.90 & & 244 \\
\hline TKS DVV & $2.65(2.43-2.86) \pm 0.62^{a}$ & $1.09 \pm 0.21^{a}$ & $244.29 \pm 52.5$ \\
\hline
\end{tabular}

Median (low quartile-upper quartile) $(n=7) . * *$ Mean \pm SD $(n=7) ;{ }^{+}$MDA equivalents; ${ }^{++}$Trolox equivalents. Values with different superscript letters $(\mathrm{a}, \mathrm{b})$ in the same row are significantly different $(p<0.05)$

The lung pathology assessment has shown that all concentrations $(200,400,800 \mathrm{mg} / \mathrm{kg}$ BW) had significant differences in perivasculitis and alveolitis (Figure 2). Peribronchiolitis scores in the 400 and $800 \mathrm{mg} / \mathrm{kg} \mathrm{BW}$ (score $=3.00 \pm 0.2$ ) were found to be significantly lower than control (3.86 \pm 0.38$)$. Moreover, a significantly lower score for granulomas could be found only in $800 \mathrm{mg} / \mathrm{kg}$ BW $(3.71 \pm 0.76)$ in comparison with the control (score=4.00). Therefore, tempe extracts administration resulted in significant changes to lung pathology characteristics, especially on perivasculitis and alveolitis in higher doses of administration (Table 3 ).

\section{Discussion}

Phenolic acids and flavonoids are phytochemicals that belong to a structural chemical class of polyphenol. In nature, these compounds are found in fruits, vegetables, cereals, and beverages [23]. Isoflavones are one of the subgroups of flavonoids in soybean. Besides the isoflavones, soybean has several bioactive components, such as saponins, phytic acids, phytosterols, trypsin inhibitors, and other basic nutritive constituents, such as lipids, vitamins, minerals, oligosaccharides, and biologically active peptides [24].

The consumption of soybean as a functional food is widely recognized for its potential health benefits. Soybeans have been found to reduce the effects of menopause, promote heart and bone health, as well as decrease the risk of diabetes [25]. It has been suggested that isoflavones and their metabolites exert their anti-inflammatory properties by modulating the peroxisome proliferator-activated receptors (PPARs) $\alpha / \gamma$. They are found to have a down-regulation influence on several pro-inflammatory cytokines, such as TNF $\alpha$, IL-6, IL-8, IL-1 $1 \beta$, or IFN- - . Additionally, the expression of proteins during the production of inflammatory mediators, like iNOS, COX-2, NFKB, is also decreased [26]. All of these aforementioned chemokines and cytokines are commonly found in the innate response to Mtb infection [27]. A previous study has shown that soy-based food supplementation produced positive effects on liver function thus improving the tolerance of antituberculosis drugs among active TB patients [28]. 
Table 3. Histological damage of lung tissue on scores of Dorman's scale

\begin{tabular}{lccc}
\hline & Perivasculitis $^{*}$ & Peribronchiolitis $^{*}$ & Alveolitis* $^{*}$ Granuloma* $^{*}$ \\
\hline Control & $4.00(3.00-4.75)^{\mathrm{b}}$ & $4.00(3.25-4.00)^{\mathrm{a}}$ & $4.00(3.00-4.00)^{\mathrm{a}}$ \\
$200 \mathrm{mg} / \mathrm{kg} \mathrm{BW}$ & $3.00(2.00-4.00)^{\mathrm{ab}}$ & $3.50(3.00-4.00)^{\mathrm{a}}$ & $2.50(1.25-3.00)^{\mathrm{a}}$ \\
$400 \mathrm{mg} / \mathrm{kg} \mathrm{BW}$ & $3.00(2.00-3.75)^{\mathrm{a}}$ & $3.00(2.25-4.00)^{\mathrm{a}}$ & $3.00(1.25-3.00)^{\mathrm{a}}$ \\
$800 \mathrm{mg} / \mathrm{kg} \mathrm{BW}$ & $3.00(2.00-3.00)^{\mathrm{a}}$ & $3.00(2.00-4.00)^{\mathrm{a}}$ & $3.00(2.00-3.00)^{\mathrm{b}}$ \\
\hline
\end{tabular}

*Median (low quartile-upper quartile) ( $n=7)$. Values with different superscript letters $(a, b)$ in the same row are significantly different $(p<0.05)$.

It has been described that a traditional SSF using microorganisms on soybean can increase the level of the aglycone isoflavones, free fatty acids, and bioactive peptides [29-31]. Tempe is a traditional soy-based food from Indonesia made by SSF using molds (e.g. Rhizopus spp.) as the starter. It is considered as a functional food that has a significant amount of isoflavone as one of its bioactive components [32]. Perhaps, tempe can be considered for one of the nutritional alternatives for undernutrition among TB active patients [33]. One of the reasons for this notion might be due to the beneficial health effects of soybean's bioactive compounds, besides its good protein content.

The results have demonstrated that even though the total phenolic and flavonoid in tempe extracts has increased, the increment of total phenolic is up to about 3.6 times of soybean. On the other hand, the increase in total flavonoid content is only approximately 1.5 times of soybean. It means the extraction method with $70 \%$ ethanol as the solvent might be able to extract more phenolic compounds than the total flavonoid from soy products or food. Furthermore, the DPPH result from the tempe extract $(30.72 \%)$ was higher than both soybean $(20.01 \%)$ and uncooked tempe (21.70\%).

Several previous studies support these results. Alcoholic extractions have shown to be better at retaining antioxidant activity in tempe compared to other solvents [34]. Pure ethanol and methanol have shown to be favorable for isoflavone extraction. However, 50 wt\% aqueous ethanol can be used to obtain high total phenolic content and AO activity extracts [35]. In brown soybean extractions using water and different concentrations $(50 \%, 75 \%, 95 \%)$ of ethanol, the $75 \%$ ethanol extract demonstrated higher DPPH antioxidant activity, total phenol, and anthocyanin content [36]. Moreover, $70 \%$ of ethanol is recommended for extracting soybean antioxidants due to the high TPC and oxygen radical absorbance capacity (ORAC) results [37]. On the other hand, solvents, such as acetonitrile, are superior to others in extracting isoflavones in soy foods [38]. However, the total phenolic content was only efficiently extracted using water as the solvent [39].

Oxidative stress (OS) arises due to the imbalance between the free ROS and antioxidant mechanisms. There is a higher risk of OS in the lung compared to other organs due to their larger surface area and high blood supply $[40,41]$. To compensate for this burden, the lung has evolved numerous antioxidant defense mechanisms. There are two distinct groups of antioxidant processes, enzymatic and non-enzymatic systems. Enzymatic antioxidant processes present in the lung, including superoxide dismutase (SOD), glutathione peroxidase, and catalase. Whereas non-enzymatic processes involve ferritin, ascorbic acid, ceruloplasmin, and carotene. Together, these antioxidant mechanisms buffer oxidants and maintain the oxidative balance in the lung [42]. However, it is important to note that such complex antioxidant mechanisms can be overwhelmed if the production of
ROS is greater than the capacity of cells to scavenge it, leading to OS.

In this study, the antioxidant activity of tempe extract may be beneficial for the histological damage in lung tissue. The positively impacted lung pathology parameters were perivasculitis, alveolitis, peribronchiolitis, and granuloma. The improvement of TAC biomarkers also exhibited the same pattern. Among TAC, TBARS, and CRP, only TAC biomarkers were lower than the control at 200, 400 , and $800 \mathrm{mg} / \mathrm{kg} \mathrm{BW}$ doses. They showed comparable results at all concentrations. However, this positive effect could be unpredictable since it described the non-dose-dependent characteristics, which implies that it may be caused by other factors as well.

Moreover, this linear pharmacokinetics (lack of dose dependence) makes it challenging to predict its hazard exposure in humans, so it is difficult to assess the appropriate concentration. The deviation from linear, dose-independent to non-linear, dosedependent pharmacokinetics extrapolating the same toxicity from high to low doses [43]. Several factors may influence the pharmacokinetics of xenobiotics, which if left unconsidered, may introduce the uncertainty into the predictions of toxicity following any chemical exposure. One of these factors is the differences of species [44].

On the other hand, the Wistar rat is a valuable model to understand the host-pathogen interactions that result in the control of TB infection and the potential establishment of latent TB. The rat is also a suitable animal model choice for TB drug discovery due to the ease of manipulation, low cost, and wellestablished use in toxicology and pharmacokinetic analyses [45]. In the last century, rats were the most used animal model in biochemical research, but in the previous two decades, its popularity decayed due to the limited ability to perform the reverse genetics in rats.

This in vivo study was not able to show a dose-response relationship of the ethanolic tempe extract with our TB animal model. This effect is the first criterion for identifying prospective active substances. The fundamental reason for such criteria is that there is a need for screening the particular compounds at lower doses or therapeutic doses, which should show a direct relationship to the biological response of interest [43]. Moreover, it has been suggested that several studies on antioxidants have failed to note any significant change in disease endpoints. The results of these studies have been interpreted as a setback for the oxidation hypothesis $[40,46]$. Perhaps it indicates the major misconceptions about the hypothesis and the unjustified outcome expectations. Incorrect selection of the sample population, endpoints that are incompatible with the hypothesis, poor choice of antioxidants, and the lack of inclusion of oxidative stress biochemical markers and vascular response are some of the contributors to the "failure" of these studies [46]. 


\section{Conclusion}

The administration of ethanolic tempe extract may result in weak positive influences on the total antioxidant activity and histological lung tissue damage. However, these beneficial effects were not described by a dose-response (non-linear) relationship. Further studies to explore these findings are warranted to clarify the underlying cellular mechanism.

\section{Acknowledgment}

The Directorate General of Higher Education of Indonesia has supported this study through a basic research grant for the university.

\section{Conflict of interest}

The authors reported no potential conflict of interest. The authors alone are responsible for the content and writing of this paper.

\section{Ethical approval}

All procedures performed in studies involving animals were in accordance with the ethical standards of the Medical Faculty of Wijaya Kusuma University, Surabaya at which the studies were conducted with number 13/SLE/FK/UWKS/III/2013 (8 March 2013).

\section{References}

1. Bolanho BC, Beleia A. Bioactive compounds and antioxidant potential of soy products. Alim Nutr Araraquara 2012; 22(4): 539-546. https://www.researchgate.net/publication/284662625 Bioactive com pounds and antioxidant potential of soy products.

2. Hillman GG, Singh-Gupta V, Hoogstra DJ, Abernathy L, Rakowski J, Yunker CK, et al. Differential Effect of Soy Isoflavones in Enhancing High Intensity Radiotherapy and Protecting Lung Tissue in a Pre-Clinical Model of Lung Carcinoma. Radiother Oncol 2013; 109(1): 117-125. https://doi.org/10.1016/j.radonc.2013.08.015.

3. Cheng KC, Wu JY, Lin JT, Liu WH. Enhancements of isoflavone aglycones, total phenolic content, and antioxidant activity of black soybean by solid-state fermentation with Rhizopus spp. Eur Food Res Tech 2013; 236: 1107-1113. https://doi.org/10.1007/s00217-0131936-7.

4. Okabe $\mathrm{Y}$, Shimazu $\mathrm{T}$, Tanimoto $\mathrm{H}$. Higher bioavailability of isoflavones after a single ingestion of aglycone-rich fermented soybeans compared with glucoside-rich non-fermented soybeans in Japanese postmenopausal women. J Sci Food Agric 2011; 91(4): 658-663. https://doi.org/10.1002/jsfa.4228.

5. Floyd K, Glaziou P, Zumla A, Raviglione $M$. The global tuberculosis epidemic and progress in care, prevention, and research: an overview in year 3 of the End TB era. Lancet Respir Med 2018; 6(4): 299-314. https://doi.org/10.1016/s2213-2600(18)30057-2.

6. World Health Organization (WHO). Global Tuberculosis Report 2019. Geneva, Switzerland: World Health Organization. 2019; 283 p. https://www.who.int/publications/i/item/global-tuberculosis-report2019.

7. Grobler L, Nagpal S, Sudarsanam TD, Sinclair D. Nutritional supplements for people being treated for active tuberculosis. Cochrane Database Systematic Rev 2016; 2016(6): CD006086. https://doi.org/10.1002/14651858.cd006086.pub4

8. Siddiqi K, Lambert ML, Walley J. Clinical diagnosis of smear-negative pulmonary tuberculosis in low-income countries: the current evidence. Lancet Infect Dis 2003; 3(5): 288-296. https://doi.org/10.1016/s14733099(03)00609-1.

9. Almirall J, Bolíbar I, Toran P, Pera G, Boquet X, Balanzó X, et al; Community-acquired pneumonia maresme study group. Contribution of C-reactive protein to the diagnosis and assessment of severity of community-acquired pneumonia. Chest 2004; 125(4): 1335-1342. https://doi.org/10.1378/chest.125.4.1335.
10. Lamsal M, Gautam N, Bhatta N, Toora BD, Bhattacharya SK, Baral N. Evaluation of lipid peroxidation product, nitrite and antioxidant levels in newly diagnosed and two months follow-up patients with pulmonary tuberculosis. Southeast Asian J Trop Med Public Health 2007; 38(4): 695-703. https://pubmed.ncbi.nlm.nih.gov/17883009.

11. Rajopadhye SH, Mukherjee SR, Chowdhary AS, Dandekar SP. Oxidative Stress Markers in Tuberculosis and HIV/TB Co-Infection. J Clin Diagn Res 2019; 11(8): BC24-BC28. https://doi.org/10.7860/icdr/2017/28478.10473.

12. Dormans J, Burger M, Aguilar D, Hernandez-Pando R, Kremer K, Roholl $P$, et al. Correlation of virulence, lung pathology, bacterial load and delayed type hypersensitivity responses after infection with different Mycobacterium tuberculosis genotypes in a BALB/c mouse model. Clin Exp Immunol 2004; 137(3): 460-468. https://doi.org/10.1111/i.13652249.2004.02551.x.

13. Clemmensen $C$, Smajilovic S, Smith EP, Woods SC, Bräuner-Osborne $H$, Seeley RJ, et al. Oral I-Arginine Stimulates GLP-1 Secretion to Improve Glucose Tolerance in Male Mice. Endocrinology 2013; 154(11): 39783983. https://doi.org/10.1210/en.2013-1529.

14. Dixit AK, Bhatnagar D, Kumar V, Chawla D, Fakhruddin K, Bhatnagar D. Antioxidant potential and radioprotective effect of soy isoflavone against gamma irradiation induced oxidative stress. Journal of Functional Foods 2012; 4(1): 197-206. https://doi.org/10.1016/i.jff.2011.10.005.

15. Abdelrazek HMA, Mahmoud MMA, Tag HM, Greish SM, Eltamany DA, Soliman MTA. Soy Isoflavones Ameliorate Metabolic and Immunological Alterations of Ovariectomy in Female Wistar Rats: Antioxidant and Estrogen Sparing Potential. Oxid Med Cell Longev 2019; 5713606. https://doi.org/10.1155/2019/5713606.

16. Xu BJ, Chang SK. A comparative study on phenolic profiles and antioxidant activities of legumes as affected by extraction solvents. $J$ Foof Sci 2007; 72(2): S159-S166. https://doi.org/10.1111/j.17503841.2006.00260.x.

17. Ainsworth EA, Gillespie KM. Estimation of total phenolic content and other oxidation substrates in plant tissues using Folin-Ciocalteu reagent. Nature protocols 2007; 2(4): 875-877. https://doi.org/10.1038/nprot.2007.102.

18. Mohd Yusof H, Ali NM, Yeap SK, Ho WY, Beh BK, Koh SP, et al. Hepatoprotective effect of fermented soybean (nutrient enriched soybean tempeh) against alcohol-induced liver damage in mice. Evid Based Complement Alternat Med 2013; 2013: 274274. https://doi.org/10.1155/2013/274274.

19. Mustika A, Agil M, Sudjarwo S, Mertaniasih NM. Extract ethanol of Centella asiatica reduce expression of Mycobacterium tuberculosis antigen on alveolar macrophage from rats lung tssue infected with Mycobacterium tuberculosis. Pathology 2016; 48(S1): S144. https://doi.org/10.1016/j.pathol.2015.12.392.

20. Ohkawa $\mathrm{H}$, Ohishi $\mathrm{N}$, Yagi K. Assay for lipid peroxides in animal tissues by thiobarbituric acid reaction. Anal Biochem 1979; 95(2): 351-358. https://doi.org/10.1016/0003-2697(79)90738-3.

21. Cao G, Alessio HM, Cutler RG. Oxygen-radical absorbance capacity assay for antioxidants. Free Radic Biol Med 1993; 14(3): 303-311. https://doi.org/10.1016/0891-5849(93)90027-r.

22. Manafe DRT, Agustiningsih D, Prasetyastuti. Effects of quercetin on the nicotine-induced oxidative status in male Wistar rats: study on creactive protein (CRP) and malondialdehyde (MDA) concentrations. J Med Sci 2016; 48(2): 81-88. http://doi.org/10.19106/JMedSci004802201602.

23. Pandey KB, Rizvi SI. Plant polyphenols as dietary antioxidants in human health and disease. Oxid Med Cell Longev 2009; 2(5): 270-278. https://doi.org/10.4161/oxim.2.5.9498.

24. Isanga J, Zhang GN. Soybean Bioactive Components and their Implications to Health - A Review. Food Reviews International 2008; 24(2): 252-276. https://doi.org/10.1080/87559120801926351. 
25. Singh BP, Yadav D, Vij S. Soybean Bioactive Molecules: Current Trend and Future Prospective. In: J Mérillon JM, Ramawat K, Eds. Bioactive Molecules in Food. Reference Series in Phytochemistry. Cham: Springer. 2017: 1-29. https://doi.org/10.1007/978-3-319-54528-8 4-1.

26. Medjakovic S, Mueller M, Jungbauer A. Potential health-modulating effects of isoflavones and metabolites via activation of PPAR and AhR. Nutrients 2010; 2(3): 241-279. https://doi.org/10.3390/nu2030241.

27. Domingo-Gonzalez R, Prince O, Cooper A, Khader SA. Cytokines and chemokines in Mycobacterium tuberculosis infection. Microbiol Spectr 2016; $\quad 4(5): \quad 10.1128 /$ microbiolspec. TBTB2-0018-2016. https://doi.org/10.1128/microbiolspec.tbtb2-0018-2016.

28. Mel'nyk VP, Anisimova luM, Borovs'ky̆̌ VR, Stadnyk LV, Svitlychna TH. Soy-based food in a complex treatment of patients with tuberculosis. Lik Sprava 2006; (8): 65-70. Ukrainian. https://pubmed.ncbi.nlm.nih.gov/17427429.

29. Ali NM, Yeap SK, Yusof HM, Beh BK, Ho WY, Koh SP, et al. Comparison of free amino acids, antioxidants, soluble phenolic acids, cytotoxicity and immunomodulation of fermented mung bean and soybean. $J \mathrm{Sci}$ Food Agric 2016; 96(5): 1648-1658. https://doi.org/10.1002/jsfa.7267.

30. Gibbs BF, Zougman A, Masse R, Mulligan C. Production and characterization of bioactive peptides from soy hydrolysate and soyfermented food. Food Research International 2004; 37(2): 123-131. https://doi.org/10.1016/j.foodres.2003.09.010.

31. Haron H, Ismail A, Azlan A, Shahar S, Peng LS. Daidzein and genestein contents in tempeh and selected soy products. Food Chemistry 2009; 115(4): 1350-1356. https://doi.org/10.1016/j.foodchem.2009.01.053.

32. Liu K. Soybeans as functional foods and ingredients. New York: AOCS Publishing. 2004; 331 p. https://doi.org/10.1201/9781003040286.

33. Fatmah. Impact of Date-tempeh Biscuit on the Nutritional Status of Stunted and Wasted Toddlers. Pakistan Journal of Nutrition 2018; 17(11): 542-549. https://dx.doi.org/10.3923/pjn.2018.542.549.

34. Chang CT, Hsu CK, Chou ST, Chen YC, Huang FS, Chung YC. Effect of fermentation time on the antioxidant activities of Tempeh prepared from fermented soybean using Rhizopus oligosporus. Int J Food Sci Tech 2009; 44(4): 799-806. https://doi.org/10.1111/j.13652621.2009.01907.x

35. Handa CL, de Lima FS, Guelfi MFG, Georgetti SR, Ida El. Multi-response optimisation of the extraction solvent system for phenolic and antioxidant activities from fermented soy flour using a simplexcentroid design. Food Chem 2016; 197(Pt A): 175-184. https://doi.org/10.1016/j.foodchem.2015.10.124.

36. Lee $\mathrm{CH}$, Hwang $\mathrm{KE}$, Kim HW, Song DH, Kim YJ, Ham YK, et al. Antioxidant activity of brown soybean ethanolic extracts and application to cooked pork patties. Korean J Food Sci An 2016; 36(3): 359-368. https://doi.org/10.5851/kosfa.2016.36.3.359.

37. Chung $\mathrm{H}$, Ji X, Canning $\mathrm{C}$, Sun $\mathrm{S}$, Zhou K. Comparison of different strategies for soybean antioxidant extraction. J Agric Food Chem 2010; 58(7): 4508-4512. https://doi.org/10.1021/jf904278r.

38. Murphy PA, Barua K, Hauck CC. Solvent extraction selection in the determination of isoflavones in soy foods. J Chromatogr B Analyt Technol Biomed Life Sci 2002; 777(1-2): 129-138. https://doi.org/10.1016/s1570-0232(02)00342-2.

39. Liu X, Chen Z. The pathophysiological role of mitochondrial oxidative stress in lung diseases. J Transl Med 2017; 15(1): 207. https://doi.org/10.1186/s12967-017-1306-5.

40. M Davies A, G Holt A. Why antioxidant therapies have failed in clinical trials. J Theor Biol 2018; 457: 1-5. https://doi.org/10.1016/j.jtbi.2018.08.014.

41. Bargagli E, Olivieri C, Bennett D, Prasse A, Muller-Quernheim J, Rottoli P. Oxidative stress in the pathogenesis of diffuse lung diseases: a review. Respir Med 2009; 103(9): 1245-1256. https://doi.org/10.1016/j.rmed.2009.04.014.

42. Shastri MD, Shukla SD, Chong WC, Dua K, Peterson GM, Patel RP, et al. Role of Oxidative Stress in the Pathology and Management of Human
Tuberculosis. Oxid Med Cell Longev 2018; 2018: 7695364. https://doi.org/10.1155/2018/7695364.

43. Tsatsakis AM, Vassilopoulou L, Kovatsi L, Tsitsimpikou C, Karamanou $M$, Leon $G$, et al. The dose response principle from philosophy to modern toxicology: The impact of ancient philosophy and medicine in modern toxicology science. Toxicol Rep 2018; 5: 1107-1113. https://doi.org/10.1016/j.toxrep.2018.10.001.

44. Martignoni M, Groothuis GM, de Kanter R. Species differences between mouse, rat, dog, monkey and human CYP-mediated drug metabolism, inhibition and induction. Expert Opin Drug Metab Toxicol 2006; 2(6): 875-894. https://doi.org/10.1517/17425255.2.6.875.

45. Singhal A, Hervé $M$, Mathys $V$, Kiass $M$, Creusy $C$, Delaire $B$, et al. Experimental tuberculosis in the Wistar rat: a model for protective immunity and control of infection. PLoS One 2011; 6(4): e18632. https://doi.org/10.1371/journal.pone.0018632.

46. Parthasarathy S, Khan-Merchant N, Penumetcha M, Khan BV, Santanam N. Did the antioxidant trials fail to validate the oxidation hypothesis? Curr Atheroscler Rep 2001; 3(5): 392-398. https://doi.org/10.1007/s11883-001-0077-9.

\section{Authors:}

Lusiani Tjandra - Lecturer, Department of Pharmacology, Faculty of Medicine, Wijaya Kusuma University, Surabaya, East Java, Indonesia. https://orcid.org/0000-0002-0387-3179.

Budhi Setiawan - Lecturer, Department of Pharmacology, Faculty of Medicine, Wijaya Kusuma University, Surabaya, East Java, Indonesia. https://orcid.org/0000-0001-6858-5656.

Kartika Ishartadiati - Lecturer, Department of Parasitology, Faculty of Medicine, Wijaya Kusuma University, Surabaya, East Java, Indonesia. https://orcid.org/0000-0001-7479-0648.

Sri Lestari Utami - Lecturer, Department of Biomedicine, Faculty of Medicine, Wijaya Kusuma University, Surabaya, East Java, Indonesia. https://orcid.org/0000-0001-8218-5966.

Jimmy Hadi Widjaja - Lecturer, Department of Pathology and Anatomy, Faculty of Medicine, Wijaya Kusuma University, Surabaya, East Java, Indonesia. https://orcid.org/0000-0002-3599-2287. 